\title{
EDUCAÇÃO INTEGRAL NA ERA DE POLÍTICAS DE RESULTADO E O MAL-ESTAR DOS COORDENADORES PEDAGÓGICOS
}

\author{
Sanny S. da ROSA ${ }^{1}$ \\ Maria Isabel PADOVAN ${ }^{2}$
}

\begin{abstract}
Resumo
Em nome da "qualidade" do ensino dimensões importantes do desenvolvimento humano têm sido negligenciadas em tempos de políticas orientadas por resultados. Este artigo coloca em pauta o conceito de educação integral no contexto de uma pesquisa colaborativa realizada em uma escola de tempo estendido do município de São Caetano do Sul/SP. Em sessões reflexivas, realizadas com coordenadores pedagógicos, procurou-se discutir práticas de trabalho que tivessem como horizonte a formação integral dos alunos. Os sentidos e significados identificados nos discursos foram analisados com base na teoria sócio-histórica e nos procedimentos dos Núcleos de Significação. Os resultados revelam entendimentos difusos e contraditórios sobre o tema, mas também o mal-estar dos coordenadores ante a lógica competitiva do modelo gerencialista a que estão submetidos. Romper com essa lógica pressupõe repensar o sentido, as temáticas e os formatos das ações formativas realizadas na escola, o que requer um rigoroso trabalho reflexivo que lhes dê sustentação.
\end{abstract}

Palavras-chave: Educação Integral. Coordenador Pedagógico. Políticas de resultado. Pesquisa Colaborativa.

\footnotetext{
${ }^{1}$ Doutora em Educação (Currículo) - PUC-SP; pós-doutoramento: IOE - University College of London; professora e pesquisadora do Programa de Pós-Graduação Stricto Sensu em Educação da Universidade Municipal de São Caetano do Sul - USCS; temas de pesquisa: políticas públicas educacionais; políticas curriculares; gestão educacional.

E-mail: sanny.rosa@prof.uscs.edu.br

${ }^{2}$ Mestre em Educação - Universidade Municipal de São Caetano do Sul - USCS; professora do ensino fundamental da rede municipal de SCS; pesquisadora do grupo de pesquisa Gestão Democrática e Qualidade Social da Educação (CNPq) USCS.

E-mail: mbel_pp@hotmail.com
} 


\title{
INTEGRAL EDUCATION IN TIMES OF RESULTS-DRIVEN POLICIES AND THE DISCOMFORT OF EDUCATIONAL COORDINATORS
}

Sanny S. da ROSA

Maria Isabel PADOVAN

\begin{abstract}
Important dimensions of human development have been neglected in the name of educational "quality" in times of results-driven policies. This article examines the concept of integral education in the context of a collaborative research project carried out in a full-time school in the city of São Caetano do Sul, São Paulo. In reflective sessions held with educational coordinators, we sought to discuss school practices that had the students' integral education as their objective. The senses and meanings identified in their discourse were analyzed with a basis on socio-historical theory and through the framework of Significance Nuclei. The results show not only diffuse and contradictory understandings of the subject but also the discomfort of coordinators faced with the competitive logic of the management model to which they are subjected. Breaking away from this logic requires reviewing the meanings, themes and forms of educational practices in schools, which demands rigorous reflective work to support them.
\end{abstract}

Keywords: Integral education. Educational Coordinator. Results-driven policies. Collaborative Research. 


\section{Introdução}

Em nome da melhoria da "qualidade" do ensino, dimensões importantes do desenvolvimento humano têm sido negligenciadas pelas escolas. Essa é uma constatação já feita por diferentes autores (DOURADO, OLIVEIRA, 2009; HYPÓLITO, VIEIRA, LEITE, 2012; 2012 BALL, 2008; BALL, MAGUIRE, BRAUN, 2012; PONCE, 2016). Mas é a partir de nossa experiência de trabalho na coordenação pedagógica de uma escola de período integral que o tema deste artigo será problematizado.

A atenção quase exclusiva dada aos aspectos cognitivos da educação com vistas a elevar os indicadores de desempenho das escolas está na origem da pesquisa relatada neste artigo. Algumas indagações decorrentes dessa situação, intensificada nas últimas décadas, podem ser levantadas: qual a finalidade de estender o tempo de permanência do aluno na escola? A jornada integral seria condição suficiente para caracterizar uma educação integral? Que arranjos pedagógicos precisariam ser observados para promover o pleno desenvolvimento dos alunos? A qualidade que buscamos tem sido orientada pela preocupação com a formação humana? O que entender, afinal, por educação integral?

Colocar em pauta essas questões é parte do trabalho formativo sob responsabilidade dos coordenadores pedagógicos, também este negligenciado frente às demandas das políticas de focadas em resultados e na produtividade docente. O que compete aos coordenadores para que as formações não fiquem restritas às propostas instrumentais de "parceiros”3 externos apresentadas como "soluções" para melhorar a qualidade do ensino? Que pautas formativas poderiam contemplar as reais necessidades dos professores? E que necessidades seriam essas?

Com tais inquietações, procuramos mobilizar a equipe pedagógica de nossa escola para refletir sobre as práticas de trabalho e sobre possíveis experiências que pudessem ampliar e enriquecer a formação dos alunos na perspectiva de uma educação integral. Entendemos que tais experiências seriam aquelas que promovessem o pensamento crítico, a convivência social digna, a sensibilidade humana e a consciência de si em suas relações com o outro. Em síntese, as que contemplam as dimensões técnica, ética, estética e política da educação de que fala Rios (1993; 2001) e que não se reduzem a competências e habilidades exigidas em avaliações externas.

Começamos por envolver quatro professoras Coordenadoras de Área (CA) que, em São Caetano do Sul, têm como atribuição oferecer apoio pedagógico aos docentes dos anos finais do ensino fundamental. Interessava-nos que se tornassem parceiras de um projeto de formação que considerasse as necessidades dos professores e dos alunos Para tanto,

${ }^{3}$ Em 2013, a Seduc de SCS firmou parceria de 18 meses com a Fundação Lemann (Programa Técnicas Didáticas. Disponível em: https://www.abcdoabc.com.br/sao-caetano/noticia/sao-caetanoassina-parceria-educacional-fundacao-lemann-9207 ; em 2015, firmou parceria com o Itaú Social (Programa Tutoria), ambos com o objetivo de capacitar os gestores e "aumentar a efetividade do trabalho dos gestores escolares na Educação Infantil e Ensinos Fundamental e Médio”. Disponível em: $\quad$ https://www.abcdoabc.com.br/sao-caetano/noticia/educacao-sao-caetano-celebra-resultadosprograma-tutoria-44448. 
optamos por desenvolver uma pesquisa colaborativa que tem no exercício reflexivo sua categoria epistemológica central. Nesse tipo de pesquisa "O conhecimento prático deve se articular ao teórico e vice-versa, portanto, refletir sobre a prática envolve tanto a necessidade de rever a teoria quanto de desvelar vicissitudes da ação docente (IBIAPINA, 2008, p. 18). O processo e os resultados dessa investigação são objetos das reflexões deste artigo, organizado em três seções.

A primeira seção situa historicamente os projetos de educação integral no Brasil destacando as abordagens em disputa. A segunda faz uma breve contextualização da rede municipal de São Caetano do Sul (SCS), caracteriza os participantes da pesquisa e descreve os procedimentos teórico-metodológicos empregados na coleta e análise dos dados. A terceira e última parte discute resultados que ofereceram pistas para repensar o sentido, as temáticas e os formatos de formação que podem ser realizados na escola pelos coordenadores pedagógicos.

\section{Políticas de Educação Integral no Brasil: entre boas intenções e efeitos de retórica}

Educação integral é tema recorrente na história da educação brasileira. De tempos em tempos volta a entrar no foco das políticas de educação que vislumbram nela uma “solução” para a qualidade de ensino. O termo “educação integral”, porém, não é autoexplicativo. Ao contrário, abriga distintas concepções, a depender das intenções do projeto social dos que o tomam como bandeira.

No Brasil, a ideia aparece pela primeira vez na década de 1930, com dois propósitos muito diferentes. A proposta defendida pela Ação Integralista Brasileira (AIB), por exemplo, visava aumentar o controle social por parte do Estado, embalada por um espírito autoritário e conservador. Em contraste, o projeto de educação integral defendido pelos Pioneiros da Educação Nova que tinha como referência os ideais de democracia liberal do filósofo norte-americano, John Dewey (1859-1952) (CAVALIERE, 2010).

Décadas adiante, e já na esteira das reformas desencadeadas com a promulgação da Lei de Diretrizes e Bases da Educação Nacional de 1996, o conceito de educação integral assume ares pós-modernos. Contudo, o embate ideológico permaneceu entre os grupos que entendem a educação a partir de uma perspectiva instrumental, técnica e pró-mercado, e os que continuaram defendendo uma educação humanista, democrática e de responsabilidade do Estado (CHIZZOTTI; PONCE, 2012). Grosso modo, a polêmica educação integral versus ensino de tempo integral têm origem nessa disputa.

Na vertente democrática, Moll (2012) localiza dois marcos históricos importantes das experiências de educação integral no Brasil. O primeiro foi a criação das EscolasParque, concebidas por Anísio Teixeira nos anos 1940. O segundo marco se deu com a criação dos Centros Integrados de Educação Pública (CIEPs), por Darcy Ribeiro, nos anos 
1980/1990. De acordo com a autora, esses dois projetos carregavam o entusiasmo de seus idealizadores de construção de uma sociedade democrática:

[...] Anísio e Darcy vinculavam seu entusiasmo educacional aos sonhos de uma sociedade efetivamente democrática que repartisse, entre todos os seus cidadãos e cidadãs, conhecimentos e vivências educativas que lhes servissem de suporte para uma inserção plena na vida em sociedade (MOLL, 2012, p. 129).

A ampliação da jornada escolar, nesses dois projetos, seria uma das condições entre outras, para que escola abarcasse "o campo das ciências, das artes, da cultura, do mundo do trabalho, por meio do desenvolvimento físico, cognitivo, afetivo, político e moral", com a finalidade de "incidir na superação das desigualdades sociais mantidas, se não reforçadas, pela cultura escolar” (MOLL, 2012, p. 129). Um dos maiores defensores da ideia de educação integral, Miguel Arroyo (1988; 2009), não faz, contudo, defesa irrestrita e incondicional da escola de tempo integral sem indagar sobre a quem e a que propósitos ela serve:

\begin{abstract}
Não se amplia o tempo para poder ensinar e aprender mais e melhor, mas para poder experimentar relações e situações mais abrangentes: alimentar-se, assear-se, brincar, relacionar-se, trabalhar, produzir coletivamente na escola. Acredita-se na força educativa de experimentar e vivenciar uma ordem, uma organização social o mais total possível (ARROYO, 1988, p. 4).
\end{abstract}

Nesse mesmo texto, o autor alerta para o fato de que as escolas de tempo integral, em geral, são pensadas para as crianças pobres das classes trabalhadoras e que nelas estão presentes uma série de preconceitos a respeito da infância e da pobreza que se busca compensar via ampliação da jornada escolar. Em trabalho mais recente, Arroyo se mantém coerente com esse pensamento, lembrando que as crianças e adolescentes precisam ser vistos "como gente e não apenas como alunos" (ARROYO, 2009, p. 53), visto que a escola não é a única instituição responsável pela formação humana e nem o único espaço onde ela acontece.

Abusamos da citação porque ela encerra o sentido de educação integral que procuramos manter no horizonte da pesquisa que mais adiante será relatada. Diz ele:

\footnotetext{
Não nascemos humanos, nos fazemos. Aprendemos a ser. Todos passamos por longos processos de aprendizagem humana. [...] Reduzir essa tensa história do direito à Educação Básica universal ao domínio de habilidades, saberes, competências pontuais é empobrecer essa história. É empobrecer o ofício dos profissionais desse direito. Quando o objeto do aprendizado vai se reduzindo [...] O magistério perde sentido histórico, a escola como processo, como tempo de ensino-aprendizagem perde sentido (ARROYO, 2009, p. 53-54, grifo nosso).
}

No final dos anos 1990, o documento da UNESCO que apresenta a proposta de educação para a sociedade do século XXI, enuncia o aprender a ser foi como um dos quatro pilares a serem observados pela educação escolar, ao lado do aprender a conhecer; aprender a fazer e do aprender a viver juntos. O desenvolvimento humano aparece como preocupação face às limitações de um modelo de crescimento econômico 
e social que não vinha se mostrando capaz de reduzir as desigualdades sociais e outros "custos” humanos e ambientais:

Tendo [...] consciência de que o modelo de crescimento atual depara-se com limites evidentes, devido às desigualdades que induz e aos custos humanos e ecológicos que comporta, a Comissão julga necessário definir a educação, não apenas na perspectiva dos seus efeitos sobre o crescimento econômico, mas de acordo com uma visão mais larga: a do desenvolvimento humano (DELORS, 2001, p.69).

Com efeito, tais diretrizes foram abraçadas pelos formuladores de políticas educacionais como meio de promover, prioritariamente, o crescimento econômico e, assim, viabilizar o projeto de globalização econômica. A superação das desigualdades foi tomada mais como estratégia para minimizar os empecilhos a esse desenvolvimento do que condição para o desenvolvimento humano. Na prática, o entendimento alargado de educação proposto no documento não predominou nas reformas educacionais que marcaram a passagem dos estados-nação para a sociedade globalizada (CHIZOTTI; PONCE, 2012).

No final dos anos 1990, os quatro pilares da educação foram incorporados ao discurso pedagógico, via Parâmetros Curriculares Nacionais (PCN), que definiu novas formas de abordar o conhecimento escolar. O aprender a conhecer foi convertido em conteúdos conceituais; o aprender a fazer, em conteúdos procedimentais; o aprender a viver juntos e o aprender a ser, em conteúdos atitudinais (COLL et al., 2000). Tudo isso ancorado em constructos teóricos que reforçariam o caráter adaptativo da "pedagogia das competências” (PERRENOUD, 2000) que serviu, sob medida, aos propósitos do projeto neoliberal para a educação. Pois essa pedagogia, que Newton Duarte denominou de pedagogias do “aprender a aprender”, limita-se a:

[...] preparar os indivíduos formando as competências necessárias à condição de desempregado, deficiente, mãe solteira etc. Aos educadores caberia conhecer a realidade social não para fazer a crítica a essa realidade e construir uma educação comprometida com as lutas por uma transformação social radical, mas sim para saber melhor quais competências a realidade social está exigindo dos indivíduos (DUARTE, 2001, p.38).

Desde então, as escolas foram incentivadas a priorizar o ensino por projetos (transversais, interdisciplinares, transdisciplinares) em detrimento dos conteúdos disciplinares. O “novo" discurso conquistou a simpatia de parte expressiva da comunidade educacional progressista, que aderiu à tese de que metodologias ativas facilitam o processo ensinoaprendizagem e contribuem para alcançar "metas objetivas, com a produção de algo que sirva como instrumento de intervenção nas situações reais (...)” (BRASIL, 1998, p. 41, grifos nossos). Sobre esse fenômeno da educação globalizada, Michael Young (2016) avalia que:

Os programas eram bem-intencionados na concepção; entretanto, ao centrarem atenção nos atributos dos alunos com frágil aproveitamento e motivação, os currículos para eles desenhados tratavam os critérios de conhecimento como se fossem flexíveis. Em consequência disso, foram projetados cursos que ofereciam poucas chances de progressão nos estudos ou de empregabilidade - esses alunos se tornaram os representantes de um grupo hoje conhecido como os “jovens que não 
estudam, não trabalham nem participam de atividades de formação” (YOUNG, 2017, p. 27)

Esse espírito pragmático e tecnicista é o mesmo que preside a Base Nacional Comum Curricular da Educação Infantil e do Ensino Fundamental e o que foi utilizado como argumento para a reforma do Ensino Médio aprovada no governo Michel Temer, aprovada inicialmente, por Medida Provisória (MP 746 de 22 de setembro de 2016) e depois convertida na Lei $n^{\circ}$ 13.415/2017 de 16 de fevereiro de 2017. Vale registro que o parágrafo único do Art. 13, que institui a Política de Fomento à Implementação de Escolas de Ensino Médio em Tempo Integral, condiciona o financiamento às escolas ao termo de compromisso a ser formalizado entre as partes, que deverá conter, no mínimo:

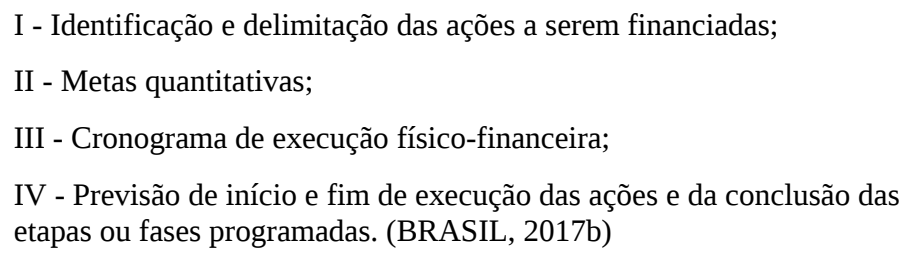

Orientados por propósitos semelhantes, alguns governos estaduais já vinham apostando na escola de tempo integral como forma de melhorar a "qualidade" do ensino. A título de exemplo, podemos citar o Programa Ensino Integral (PEI), instituído pela Lei Complementar no 1.164, de 4 de janeiro de 2012, que ampliou a jornada em escolas do ensino médio da rede estadual de educação de São Paulo. De acordo com as Diretrizes desse Programa, a ampliação da jornada "é uma estratégia fundamental para viabilizar metodologias que deverão elevar os indicadores de aprendizagem dos estudantes em todas as suas dimensões.” (SÃO PAULO, s/d., p. 11-12, grifos nossos).

Até mesmo na nomenclatura do Programa transparece o entendimento de que educação se restringe ao ensino; que integral se refere à ampliação do tempo de permanência diária na escola; e que qualidade equivale à elevação dos indicadores de aprendizagem. A abordagem gerencialista do PEI fica nítida nesta passagem do documento ao explicitar que os instrumentos de gestão do programa permitem:

\section{[...] acompanhar e monitorar o trabalho pedagógico [...] estabelecer os acordos quanto aos resultados pretendidos e as suas estratégias permitem, após a análise de indicadores, a correção dos caminhos perseguidos para a qualidade do processo de ensino e de aprendizagem. (SÃO PAULO, s/d, p. 11, grifos nossos).}

Em nome do suposto interesse e/ou necessidade dos alunos, essa concepção instrumental de educação atende, antes, os interesses do mercado de trabalho e dos empresários da educação (FREITAS, 2014). Justifica-se, assim, a cautela de Miguel Arroyo (1988; 2009) de não defender incondicionalmente a escola de tempo integral sem antes saber a quem ela de fato se destina e a quais propósitos ela serve.

Em contraste, o Programa Mais Educação, criado em 2007 pelo governo federal, sustentava entendimento diverso sobre a finalidade da ampliação do tempo de permanência do aluno na escola. O documento que orientava a implementação do Programa vinculava a ampliação do tempo a uma proposta de educação integral, argumentando que: 
(...) a extensão do horário escolar, por si só, não garante o incremento qualitativo do ensino. Aumentar a jornada de trabalho escolar dos alunos em disciplinas específicas, como Matemática ou Língua Portuguesa, oferecendo apenas mais do mesmo, gera hiperescolarização, com efeitos negativos (BRASIL, 2011, p. 24, grifos nossos).

No entendimento do Mais Educação, a ampliação da jornada não deveria se restringir à divisão das atividades em turnos escolares, a fim de evitar a diferenciação valorativa entre as atividades pedagógicas regulares a as demais dimensões formativas da criança e do jovem.

A formulação de uma proposta de Educação Integral implica ampliação qualificada do tempo, mesclando atividades educativas diferenciadas. Ao faze-lo, contribui para a formação integral do aluno, superando a fragmentação, o estreitamento curricular e a lógica educativa demarcada por espaços físicos e tempos rígidos. Nesse sentido, entende-se que a extensão do tempo - quantidade - deve ser acompanhada por uma intensidade do tempo - qualidade- nas atividades que constituem a jornada ampliada na instituição escolar (BRASIL, 2011, p.24, grifos originais).

Fica nítida a diferença de enfoque desta proposta e a dos programas antes mencionados, não apenas em relação ao uso do tempo, mas à concepção de qualidade. Para o Mais Educação qualidade dizia respeito à dimensão social do trabalho educativo, construído em processos democráticos de gestão participativos e com base nos princípios do projeto político-pedagógico da escola.

O projeto político-pedagógico tem por princípio superar a recorrente divisão social do trabalho e as práticas autoritárias existentes na escola. Nesse sentido, cabe às direções potencializar a participação social: dos conselhos escolares, dos grêmios estudantis, das associações de pais, de moradores, dentre outros constituídos na comunidade que queiram participar, solidariamente, do projeto escolar, bem como conselho de idosos, de mulheres, os movimentos negros, de artistas e outros (BRASIL, 2009, p.38).

Imediatamente após o impeachment de Dilma Rousseff, em 2016, o governo Michel Temer substituiu o Mais Educação pelo Novo Mais Educação, reduzindo os objetivos da escola de tempo integral à melhoria "da aprendizagem em língua portuguesa e matemática no ensino fundamental” (BRASIL, 2016, grifos nossos). Com esse retrocesso, encerrava-se mais um capítulo da história da educação brasileira em que se tentou fazer das escolas de tempo integral espaços de educação integral.

Em síntese, pode-se afirmar que as diretrizes da UNESCO para a Educação do Século XXI inauguraram uma nova fase de entusiasmo e otimismo pedagógico no Brasil (NAGLE, 2001). Não foram poucos os que, naquele momento social e político da história brasileira, confundiram a retórica dos organismos internacionais com a genuína disposição de promover a redemocratização da sociedade brasileira e reduzir as desigualdades sociais por meio educação. A despeito de alguns avanços obtidos, no balanço geral, prevaleceram as reformas educacionais orientadas pela teoria do capital humano (PONCE; ROSA, 2014). Na prática, os ideais democráticos que inspiraram experiências autênticas de educação integral sucumbiram ao pragmatismo hegemônico vigente em tempos neoliberais. 
Com essa breve retrospectiva, é preciso dar razão à Miguel Arroyo (1988; 2009) e admitir que ampliar o tempo de permanência de alunos e professores na escola não necessariamente se presta à concretização de uma proposta de educação integral. Levar a cabo esse projeto pressupõe, antes, disposição política e compromisso com a formação humana, da qual a escola pode ser solidária em conjunto com outros atores, como a família, a comunidade e as instituições de difusão cultural.

No microcosmo escolar, o coordenador pedagógico (CP) é um dos atores chave desse projeto. Tarefa nada fácil, uma vez que a ele tem sido atribuída a responsabilidade de articular ações pedagógicas às intencionalidades políticas que ultrapassam os muros da escola. Para não submeter os professores a "capacitações" enlatadas, vendidas como “soluções” que não levam em conta a realidade dos alunos e de cada unidade escolar, o trabalho formativo na escola precisa ser repensado.

Sob responsabilidade do CP, essa formação pressupõe abrir espaços de escuta e diálogo com os professores, o que requer estabelecer vínculos de confiança duradouros entre os docentes e a equipe gestora. Por acreditarmos que somente nessas condições é possível construir uma cultura de reflexão e colaboração em torno de um projeto pedagógico comum foi que pensamos e desenvolvemos o projeto de pesquisa/formação que passaremos a relatar.

\section{O contexto e os procedimentos da pesquisa-colaborativa}

São Caetano do Sul (SCS) é um município do Grande ABC Paulista, conhecido como "berço" da indústria automobilística brasileira, pertencente à região metropolitana de São Paulo. Município mais rico da região, São Caetano do Sul se orgulha de ter

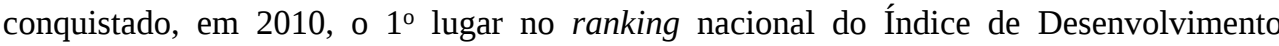
Humano Municipal, vitrine política que as diferentes administrações públicas se desdobram para manter. Com uma população estimada de 149 mil habitantes, em uma área de apenas 15,3 km2, o sistema público de ensino de SCS atende 100\% das crianças na etapa do ensino fundamental nas 20 escolas o compõem. Alguns dados ilustram (Tabela 1) por que o município se mantém como referência nacional no ensino público, "com índices de escolaridade comparáveis a de países de Primeiro Mundo”.

Tabela 1: Índice Desenvolvimento Humano Municipal - Educação/2010

\begin{tabular}{|c|c|c|c|c|}
\hline $\mathbf{2 5}$ anos ou mais & Analfabeto & $\begin{array}{c}\text { Ensino Fundamental } \\
\text { Completo }\end{array}$ & $\begin{array}{c}\text { Ensino Médio } \\
\text { Completo }\end{array}$ & $\begin{array}{c}\text { Ensino } \\
\text { Superior } \\
\text { Completo }\end{array}$ \\
\hline São Caetano do Sul & $1,76 \%$ & $73,90 \%$ & $60,61 \%$ & $31,19 \%$ \\
\hline Brasil & $11,82 \%$ & $50,75 \%$ & $35,83 \%$ & $11,27 \%$ \\
\hline
\end{tabular}

Fonte: Adaptada pelas autoras/ dados do Atlas do Desenvolvimento Humano/2010

Os servidores da educação municipal são admitidos por concurso público, com exceção dos cargos de gestão (diretores/coordenadores pedagógicos), cujo acesso se dá por 
indicação política. O número reduzido de escolas possibilita que a maioria dos professores se conheçam, característica que, de um lado, viabiliza parcerias mas, de outro, promove um clima de vigilância constante entre eles. Segundo Garcia e Prearo (2015), São Caetano do Sul reúne as escolas mais centralizadoras e o que mais inibe a gestão democrática entre os sete municípios que compõem a Região do Grande ABC.

A escola onde a pesquisa foi realizada está localizada em um bairro central de classe média alta. As mulheres predominam entre os docentes (80\%), o que se repete entre coordenadores pedagógicos do município (83\%). A faixa etária de 30 a 39 anos é a que concentra o maior número de docentes (40\%); 82\% possui formação em nível superior (bacharelado e licenciatura) obtida em instituições privadas; 40\% pelo menos uma pósgraduação lato sensu, sendo que apenas uma professora possuía, à época, o título de mestre. Quanto ao tempo de magistério, 25\% tem de 6 a 10 anos de experiência e outros 25\% exerce a profissão há no mínimo 16 anos; 65\% trabalha na mesma escola entre 3 e 10 anos. Esses dados, relativos a 20 professoras coordenadoras dos anos finais do ensino fundamental, foram obtidos, em 2018, por meio de questionário adaptado da Prova Brasil (2013).

Quanto à rotina de trabalho (Tabela 2), chama a atenção que a maior parte do tempo do CP é ocupada com atividades burocráticas relacionadas às avaliações (internas e/ou externas) e ao atendimento de casos de indisciplina e conflito entre os alunos. A falta de tempo para as atividades pedagógicas foi uma das queixas confirmadas na etapa qualitativa da pesquisa.

Tabela 2: Rotina dos Coordenadores Pedagógicos do Município de São Caetano do Sul

\begin{tabular}{|c|c|c|c|c|}
\hline Rotina de trabalho & Nunca & Raramente & Às vezes & Sempre \\
\hline $\begin{array}{c}\text { Realiza estudos/cursos para desenvolvimento da } \\
\text { função (CP) }\end{array}$ & $0 \%$ & $17 \%$ & $42 \%$ & $41 \%$ \\
\hline Participa da formação contínua dos professores. & $0 \%$ & $8 \%$ & $33 \%$ & $59 \%$ \\
\hline Prepara atividades de formação para o HTPC & $0 \%$ & $8 \%$ & $25 \%$ & $67 \%$ \\
\hline $\begin{array}{c}\text { Auxilia os professores na elaboração de aulas e } \\
\text { atividades. }\end{array}$ & $0 \%$ & $25 \%$ & $58 \%$ & $17 \%$ \\
\hline Atende os professores & $0 \%$ & $0 \%$ & $0 \%$ & $100 \%$ \\
\hline $\begin{array}{l}\text { Acompanha/ auxilia o trabalho dos professores/alunos } \\
\text { (elaboração de aulas/ atividades/avaliação) }\end{array}$ & $0 \%$ & $8 \%$ & $25 \%$ & $67 \%$ \\
\hline $\begin{array}{c}\text { Realiza serviços burocráticos relacionados ao trabalho } \\
\text { pedagógico (organiza materiais solicitados pelos } \\
\text { professores/xerox, livros, e materiais para outras } \\
\text { atividades como festas, projetos etc.) }\end{array}$ & $0 \%$ & $0 \%$ & $8 \%$ & $92 \%$ \\
\hline $\begin{array}{l}\text { Realiza serviços burocráticos relacionados às avaliações } \\
\text { externas (gráficos, planilhas, relatórios, etc.) }\end{array}$ & $0 \%$ & $8 \%$ & $17 \%$ & $75 \%$ \\
\hline $\begin{array}{l}\text { Envolve-se na preparação de alunos/professores para as } \\
\text { avaliações externas }\end{array}$ & $0 \%$ & $0 \%$ & $25 \%$ & $75 \%$ \\
\hline $\begin{array}{l}\text { Discussão e análise dos resultados das avaliações } \\
\text { externas para reavaliação do Projeto Político- } \\
\text { Pedagógico }\end{array}$ & $0 \%$ & $0 \%$ & $17 \%$ & $83 \%$ \\
\hline
\end{tabular}


Fonte: Dados coletados pelas autoras com base no Questionário Contextual do Diretor Prova Brasil/ 2013.

Foi nesse cenário que realizamos, em 2016-2017, a pesquisa colaborativa com quatro Coordenadores de Área (CA) das seguintes áreas curriculares dos anos finais do ensino fundamental: Língua Portuguesa e Inglês; História e Geografia; Matemática e Ciências; Educação Física e Artes. Foram realizadas quatro sessões reflexivas, com as seguintes pautas, previamente definidas com as participantes, sobre tema educação integral (EI): a) EI e qualidade social da educação; b) EI e formação de valores; c) EI e as competências do educador; d) EI e vivências pedagógicas significativas.

Seguindo os procedimentos metodológicos propostos por Ibiapina (2008), as sessões foram organizadas em quatro momentos. O primeiro, chamado de descrição, tem o objetivo de descrever a prática e explicar suas razões (o que faço e por que faço assim?). O segundo é o da informação e visa alimentar o grupo com aportes que ofereçam consistência teórica às reflexões, com auxílio de textos, vídeos e outros recursos. No terceiro - chamado de confronto - o grupo retoma as discussões iniciais confrontando-as com conceitos teóricos da etapa anterior, com o objetivo de repensá-las, agora, de forma mais crítica. As sínteses produzidas são feitas no quarto e último momento, denominado de reconstrução, com o objetivo de propor alternativas às práticas escolares.

Alguns cuidados foram tomados na preparação e condução das sessões reflexivas que, em média, tiveram duração de $1 \mathrm{~h} 30$ minutos. A cada encontro fazia-se uma breve retomada das reflexões anteriores, de modo que as elaborações fossem tomando corpo e pudessem ser apropriadas pelo grupo. Com o livre consentimento das participantes, as discussões foram gravadas e, posteriormente, transcritas para a análise. Não menos importante foram os cuidados com a organização do espaço: cadeiras nomeadas, flores na mesa, pautas e textos em pastas individuais, água e até "mimos" personalizados. Esses detalhes contribuem para estabelecer vínculos de confiança, indispensáveis ao trabalho colaborativo.

A análise dos registros orais e escritos foi feita com base nos procedimentos teóricometodológicos dos Núcleos de Significação (AGUIAR; OZELLA, 2013). Por essa abordagem sócio-histórica busca-se apreender os significados e sentidos atribuídos pelos sujeitos aos temas em discussão, e não apenas descrever o conteúdo dos registros. O ponto de partida são os significados, pois:

\begin{abstract}
São eles que permitem a comunicação, a socialização de nossas experiências. Muito embora sejam mais estáveis, "dicionarizados", eles também se transformam no movimento histórico, momento em que sua natureza interior se modifica, alterando, consequentemente a relação que mantêm com o pensamento, entendido como um processo (AGUIAR; OZELLA, 2013, p. 304).
\end{abstract}

As autoras explicam ainda que "por meio de um trabalho de análise e interpretação pode-se caminhar para as zonas mais instáveis, fluidas e profundas, ou seja, para as zonas de sentido.” (AGUIAR, 2006, p.14, grifo nosso). Após leituras sucessivas e sistemáticas do material coletado, identificam-se as ideias e expressões mais significativas, seja pela 
frequência com que ocorrem, pelas contradições que revelam ou, ainda, pelo que permitem entrever nas entrelinhas do que é dito ou silenciado. Trata-se de um trabalho complexo, pois:

O sentido coloca-se em um plano que se aproxima mais da subjetividade, que com mais precisão expressa o sujeito, a unidade de todos os processos cognitivos, afetivos e biológicos. Assim, para avançar na compreensão dos sentidos, em nossas análises temos de considerar que todas as expressões humanas são cognitivas e afetivas (AGUIAR, 2006, p.15).

Operacionalmente, o trabalho de análise se dá em três etapas: a primeira consiste no levantamento de pré-indicadores, cujo ponto de partida é a palavra; em seguida, é feita a aglutinação desse material para extrair os indicadores; finalmente, na terceira, identificamse os Núcleos de Significação. Esse processo é assim explicado pelos autores:

[...] nas diversas leituras do material transcrito, destacamos conteúdos das falas do professor que sejam reiterativos, que demonstrem maior carga emocional ou ambivalências. Esses conteúdos são chamados de pré-indicadores e, geralmente, apresentam-se em grande número e irão compor um quadro amplo de possibilidades para a organização dos núcleos. Os pré-indicadores são, portanto, trechos de fala compostos por palavras articuladas que compõem um significado, carregam e expressam a totalidade do sujeito e, portanto, constituem uma unidade de pensamento e linguagem. Um critério básico para filtrar estes pré-indicadores é verificar sua importância para a compreensão do objetivo da investigação (AGUIAR; OZELLA, 2013, p.309).

Finalizada a aglutinação dos pré-indicadores em indicadores, chega-se aos Núcleos de Significação, um trabalho que se subdivide ainda em duas fases:

\begin{abstract}
Uma voltada para a inferência e organização dos núcleos de significação, a partir da articulação de indicadores, e outra que se ocupa da discussão teórica dos conteúdos propriamente ditos que constituem tais núcleos, isto é, a interpretação dos sentidos, que, produzidos na atividade social e histórica, configuram o modo de pensar, sentir e agir dos sujeitos participantes da pesquisa (AGUIAR; SOARES; MACHADO, 2015, p. 71).
\end{abstract}

No próximo tópico, apresentaremos os resultados obtidos, que nos deram pistas importantes para repensar o trabalho da coordenação pedagógica da escola na perspectiva da gestão democrática e da educação integral dos alunos.

\title{
Significados e sentidos atribuídos à educação integral
}

A análise dos registros das sessões reflexivas permitiu que chegássemos a dois grandes Núcleos de Significação. O primeiro núcleo (Quadro 2) foi composto por indagações, formulações e afirmações que expressam a tentativa do grupo de apropriar-se do conceito de educação integral; o segundo núcleo (Quadro 3), concentrou formulações acerca das condições necessárias para a construção de um trabalho colaborativo que caminhasse na direção da educação integral. 
Quadro 2: Núcleo de Significação I

\begin{tabular}{|c|c|}
\hline \multicolumn{2}{|c|}{ Educação Integral não é um “evento” } \\
\hline Indicador 1 & Integral é o quê? \\
\hline Indicador 2 & Formar para competir? Mas, a gente não pode fazer só isso! \\
\hline Indicador 3 & Os alunos pensam; eles têm opinião. \\
\hline
\end{tabular}

Fonte: Elaborado pelas autoras

Na busca pelo entendimento do conceito, as CA excluíram aquilo que, para elas, educação integral não é, concluindo que EI não se confunde com escola de tempo estendido. A dimensão do tempo, no entanto, emergiu com o sentido de continuidade e permanência, como expressam as seguintes formulações:

Integral é tempo? Não, não de tempo (...) há uma grande diferença de uma escola integral e uma educação integral. (PCA 1)

Se a escola favorece a educação integral? Na minha opinião, não. Porque não adianta nada eu pensar no mês, em dois meses, no trimestre. Eu tenho que pensar isso no todo (...) e não simplesmente lançar como se fosse um evento. Essas coisas não são um evento. Não é uma coisa esporádica, não pode ser. (PCA 3)

Outro sentido associado à EI foi a sua abrangência. Para o grupo, um projeto educativo com essa finalidade englobaria todos os aspectos da formação do aluno, e não apenas os conteúdos valorizados pelas avaliações externas. Nesse sentido, EI foi associada à tarefa socializadora da escola e à formação para a vida.

Uma educação integral é você englobar todas as áreas, não só o português, a matemática, mas o que a gente usa aqui fora. É a ética? É a socialização? (PCA 2)

A gente tem que aprender isso na escola...Porque o primeiro contato que eles têm com a grande sociedade, tirando a casa, é na escola... A gente tem que educar para a vida. (PCA 1)

Educar para a vida aparece, aqui, com o sentido de ampliar o universo de vivências dos alunos, para além de seus círculos familiares. O papel social e político da educação escolar se insinua como preocupação, por exemplo, no seguinte diálogo a respeito de "por onde começar” o trabalho:

[...] não adianta a gente idealizar alguma coisa no micro, eu tenho que pensar no macro, porque senão a gente acha que o projeto não teve função. (PCA 3)

[...] eu já acho que tudo tem começar no micro, porque você nunca vai atingir o macro. (PCA 2)

Refletir se a escola - e os professores - devem começar pelo "micro" ou pelo "macro" permitiu problematizar a complexidade, as contradições, os limites e as possibilidades da tarefa educativa da escola. Ainda que incipientes, essas discussões ajudaram a pensar a educação como vida na polis, uma reflexão que frequentemente é esquecida ou reduzida a discursos esvaziados sobre "educação e cidadania".

Instigadas a refletirem sobre o caráter transcendente da educação, debate sobre EI evoluiu para a dimensão ética e da educação. Em Hanna Arendt, por exemplo, encontramos 
uma referência importante para pensar a respeito dessas duas dimensões da educação, entendida, nesse trecho, como bem público de direito de todos.

O mundo comum é aquilo que encontramos ao nascer e aquilo que deixamos para trás quando morremos. O público tem o sentido daquilo que transcende nossa vida e refere-se tanto ao passado como ao futuro: É o caráter público da esfera pública que é capaz de absorver e dar brilho através dos séculos a tudo o que os homens venham a preservar da ruína natural do tempo (ARENDT, 2008, p.65).

Outros elementos que aludem aos valores cultivados na escola também emergiram nas reflexões do grupo. Frente ao dilema sobre se cabe à escola formar para o convívio social solidário ou para as demandas do mercado de trabalho, posições conflitantes e tentativas de conciliação apareceram nas falas das CA, momento em que emergiu um claro sentimento de mal-estar:

A gente vai fazer o que o mercado pede, mas a gente não pode fazer só isso. (PCA 1)

Nós temos profissionais que passam muito esse lado pessoal, aqueles que são muito competitivos, eles passam esse espírito para os alunos, de competitividade. (PCA 3)

[...] o que me choca é que tem vários professores de matemática que focam muito no IDEB, nessa parte de competitividade e que só querem os melhores alunos. (PCA 2)

Ele [aluno], precisa competir e ser solidário na competição. Não adianta nada eu ganhar sozinho. Eu preciso ganhar no coletivo. Que eu sozinho não sou nada. (PCA 4)

As contradições e conflitos presentes nessas falas são melhor compreendidas quando se leva em conta o contexto da escola, uma das primeiras do ranking do ABC Paulista. Manter essa posição tem sido forte fator de pressão sobre a equipe escolar. Justamente por isso, a preocupação de ouvir os alunos apareceu como contraponto ao clima competitivo que permeia a convivência nessa unidade escolar.

Ah, eu pensei no aluno e tudo que ele traz de bagagem para a aula. A cidade onde ele vive, a família, os amigos da escola, também fazem pressão em cima dele. (PCA 2)

Ouvir também [é importante] porque os alunos...eles pensam. E pensam, na grande maioria, às vezes, diferente da gente.... Eles são alunos que têm opinião. Então, o professor tem que ouvir isso, e aí sim você vai formar um ensino integral. (PCA 3)

$E$ É e foge um pouco do seu planejamento, porque é o que você sente, no momento, que às vezes precisa ser passado. Quantas vezes a gente planeja algo e chega na hora $H$, você sente outra necessidade. (PCA 1)

E a gente trabalha e põe eles para pensar. O tema às vezes não é legal Não é legal, mas com o rap eles conseguem trazer... Um dia eu precisava trabalhar com problema de droga para eles poderem entender aonde se chega com isso...[porque alguns alunos meus estavam com problemas de droga]. E tinha também o conteúdo da disciplina, mas ficou em segundo plano, porque o plano maior era atingi-los de uma outra forma. (PCA 2)

No primeiro Núcleo foi possível identificar temas latentes e pautas que mereceriam ser aprofundadas, como a identificação das razões que estão na origem das angústias e do mal-estar existente entre elas. Já no segundo Núcleo (Quadro 3) os indicadores referem-se à 
necessidade de criar e consolidar espaços de escuta e diálogo entre os docentes e a coordenação, condição para o trabalho coletivo e para a construção de relações mais democráticas no interior da escola.

Quadro 3: Núcleo de Significação II

\begin{tabular}{|l|r|}
\hline \multicolumn{2}{|c|}{ Trabalho Colaborativo: entre a necessidade de diálogo e a dificuldade de escuta } \\
\hline Indicador 4 & Mudar depende dos professores, mas “eles” não olham o todo. \\
\hline Indicador 5 & Ouvir para dialogar: “ A gente é um grupo!” \\
\hline Indicador 6 & Trabalho colaborativo: “É difícil, mas é preciso tentar.” \\
\hline
\end{tabular}

Fonte: elaborado pelas autoras

Os indicadores desse Núcleo denotam que o trabalho coletivo é ainda um ideal distante. A situação de isolamento em que se encontram reflete o clima competitivo da escola, que se reproduz na relação dos docentes com as CA. Observa-se, nas falas, a tendência de atribuir ao outro a culpa pelos empecilhos ou por aquilo que "falta" para que o trabalho coletivo aconteça:

Existem alguns indivíduos da escola que trabalham a carreira deles, a aula deles o que se propuseram a fazer aquele ano. Eles não olham o todo. (PCA 4)

A nossa escola, ela é... plural. Nós temos o educador que faz educação, e tem o cara que vai lá e joga [conteúdo], joga, joga, joga, é isso. E nós temos que conversar, trabalhar... E tem aqueles que não sabem o que estão fazendo... Nós temos de tudo aqui. (PCA 1)

Se vai dar certo, eu vou fazer; se aquele colega não está comprando a minha ideia, bom... que pena! Eu vou fazer, quem sabe ele olha e se sensibiliza? Era o que eu fazia, e que eu tenho feito até hoje. Tem hora que eu consigo, tem hora que não. Tem hora que eu quebro a cara, tem hora que dá muito certo. (PCA 3)

Embora o trabalho coletivo seja reconhecido como necessário, ele é visto como prática "muito difícil”. A esperança de que a cultura de isolamento e fragmentação venha a ser quebrada por professores "mais novos" joga para o outro e para o futuro a possibilidade de mudança.

Eu tenho esperança nessa geração [nova] de professores que vem. Porque ela já está sendo moldada lá na universidade, certo? E os professores de longa data, às vezes, falam: 'Pô, mas... está dando certo há tanto tempo, por que é que eu tenho que mudar?' Então, para sensibilizar este professor, vai anos, não é? (PCA 4)

$O$ educador deve estar em constante aprendizagem, lembrar que o professor especialista não está sozinho com a turma e é necessário trabalhar em grupo; discutir e encontrar meios de que os conhecimentos se entrelacem. (PCA 3)

[o que precisamos] é criar momentos nos $\mathrm{HTPC}(\mathrm{s})$ em que os professores se percebam como grupo e que o trabalho/olhar seja em grupo. A gente é uma sociedade, a gente é um conjunto, a gente é um grupo! (PCA 1) 
A expressão "a gente é um grupo" soa mais como expressão de um desejo do que realidade vivida. O sentido subjacente a essa fala diz respeito à demanda por espaços de escuta e diálogo, identificado nas seguintes propostas:

Tempos coletivos para discussões de área e de segmentos. Essas trocas são indispensáveis para a qualidade do trabalho das turmas. (PCA 2)

Talvez proporcionar momentos de reflexão ou dinâmicas (como a que fizemos hoje) para provocar uma reflexão sobre a preparação e aplicação das aulas. (PCA 1)

Acho um tanto utópico (visto trabalharmos com professores cujos pontos de vista estão, em alguns casos, "impermeáveis" a sugestões), porém a tentativa sempre é válida. (PCA 3)

Penso/idealizo uma proposta que se iniciaria com uma forte sensibilização para os educadores, pois se o profissional não estiver "conectado" com a ação, os alunos não irão se envolver da mesma forma. Partindo desse princípio, seriam criadas ações práticas desvinculadas de resultados competitivos, ou seja, propostas coletivas e cooperativas. (PCA 4)

[...] essas conversas/reuniões reflexivas resgatam a vontade de trabalhar várias habilidades dos educandos. (PCA 2).

Como síntese dos dois Núcleos, pode-se inferir que o mal-estar identificado entre os profissionais desta escola é efeito do ambiente competitivo, de disputa e cobrança que permeia o exercício da profissão docente na atualidade. Dentre as causas associadas a esse mal-estar, autores como Sacristán (1999), Esteve (1999), Nóvoa (1999), Fullan e Hargreaves (2000), Pérez Gomes (2001), apontam a intensificação do trabalho docente, o isolamento, o individualismo, a perda de autonomia. A essas causas, acrescentamos a fragilização dos laços sociais e o clima de desconfiança e vigilância que paira nas escolas. Para romper com essa lógica, é fundamental que:

[...] o coordenador pedagógico seja alguém que saiba ouvir, pois o ato de ouvir traz ao outro, enquanto ele fala, mudança na forma de se perceber, faz com que ele perca o medo de apresentar-se... $\mathrm{O}$ ato de ouvir permite ao outro tomar consciência de si e assumirse como sujeito (ALMEIDA; PLACCO, 2012, p. 21).

Nosso estudo apontou, contudo, que os coordenadores pedagógicos têm sido vítimas do mesmo mal-estar que atinge os professores e que eles também sofrem com a ausência de espaços de diálogo e escuta em que possam compartilhar suas fragilidades e incertezas diante da profissão. Essa constatação coloca a escola diante de desafio adicional: cuidar, ouvir e respeitar aqueles a quem é atribuída a responsabilidade pelos processos formativos na escola. Um desafio a ser enfrentado em terreno adverso, posto que todos têm sido alvo de políticas que buscam regular, normatizar e padronizar o trabalho escolar em busca por resultados. Para Fullan e Hargreaves (2000, p. 35) essas políticas tendem a corroer "o seu profissionalismo e os princípios morais em que se baseiam”. 
Em ambiente tão adverso e diante da consolidação das políticas orientadas por resultados, novos e mais difíceis obstáculos se interpõem às intenções e às práticas que visam a formação integral dos alunos. Com efeito, as contradições e paradoxos que emergem em meio a esse sentimento de mal-estar precisam ser trabalhadas de modo a convertê-las em movimentos de resistência.

\section{Considerações finais}

As reflexões feitas neste texto tiveram origem em preocupações com a excessiva atenção dada à dimensão cognitiva da educação escolar em meio à cultura competitiva instalada pelas políticas de resultados. Em consequência, as escolas acabam por negligenciar outros aspectos da formação, indispensáveis à convivência social digna, ao desenvolvimento da sensibilidade humana, da consciência de si e das relações com o outro. A educação integral emergiu, assim, como eixo central da pesquisa colaborativa relatada neste trabalho.

A análise dos dados confirmou o que, em nossa experiência empírica, já havíamos constatado: o tempo da escola tem sido absorvido quase que totalmente com atividades burocráticas, particularmente, aquelas voltadas às avaliações de desempenho e à mediação de conflitos. Em tais condições, o trabalho de professores e coordenadores pedagógicos é marcado pela fragmentação e pela dispersão, o que os afasta do propósito central da educação escolar: ajudar no processo de desenvolvimento e formação plena dos alunos para a vida e para o convívio social democrático.

A análise das elaborações feitas pelos coordenadores de área (CA) nas sessões reflexivas indicou que, embora difusos e contraditórios, os significados e sentidos atribuídos à educação integral se identificam com valores humanistas que conflitam com o clima competitivo vivido na escola. As tensões entre esses dois entendimentos sobre o papel da escola geram um mal-estar que vem à tona quando o tema é colocado em questão.

Esse mal-estar é produto, em última instância, da lógica e dos valores que regem a vida social na contemporaneidade e que, inexoravelmente, atingem a vida da escola: a competição e o individualismo. Como efeito, tem-se um quadro caracterizado pelo isolamento dos profissionais, a exiguidade de espaços/tempos para o diálogo e a perda de autonomia sobre a condução de seu próprio trabalho. Acrescentamos a esses efeitos, a fragilização dos laços de confiança entre docentes e gestores que inibe a possibilidade de construírem uma compreensão mais clara e crítica sobre os determinantes (históricos, sociais, políticos) que residem na raiz desse mal-estar. De algum modo, a desconfiança e a competição explicam a tendência observada de responsabilizar o outro pelo que não vai bem na escola.

Reside aí, a nosso ver, um dos grandes desafios do coordenador pedagógico preocupado com a formação integral dos alunos e com a convivência democrática com seus pares: construir e/ou restaurar os laços de confiança necessários ao engajamento de todos com um projeto educativo comum. Outro desafio é resistir às prescrições que 
invadem os espaços de formação, com vistas à "capacitar" os docentes a obterem melhores “resultados”. Antes, seria preciso colocar na agenda dos coordenadores discussões de fundo sobre as razões responsáveis por esse mal-estar. E, no que tange às propostas de educação de tempo integral, colocar em questão a quem e a quais propósitos elas se dirigem.

As políticas que associam qualidade a indicadores de desempenho não têm apenas um entendimento restrito de educação, elas sustentam uma visão equivocada sobre o sentido da escola e de sua relação com o tempo. Ao reduzirem a finalidade da escola ao desenvolvimento de competências e habilidades, reduzem a educação a um projeto individual, de curta duração e com baixo valor de troca. Formar, em sentido pleno, implica não perder de vista o caráter transcendente da educação como bem público, cuja qualidade só pode ser aferida em perspectiva histórica, isto é, pelos efeitos sociais que for capaz de produzir ao longo do tempo.

Entende-se por transcendência o que afirma Hanna Arendt (2008, p. 65) a respeito da própria condição humana: "É o caráter público da esfera pública que é capaz de absorver e dar brilho através dos séculos a tudo o que os homens venham a preservar da ruína natural do tempo." Manter no horizonte o caráter público e histórico da educação é resgatar o sentido essencial da escola como espaço de socialização de conhecimentos e convivência social. Sentido que não se aplica apenas aos alunos, mas também aos docentes e gestores pedagógicos que, em meio a tantas pressões e urgências, carecem de oportunidades de ampliar seus repertórios de conhecimento e de espaços de diálogo e escuta.

A pesquisa relatada neste texto mostra que a escola se tornou refém de uma lógica estranha aos seus profissionais. Além disso, que as atribuições do coordenador pedagógico, sob o gerencialismo, reforçam o mal-estar que permeia o dia a dia de seu trabalho. Repensar o sentido, as temáticas e o formato dos processos formativos realizados na escola, com base em um trabalho reflexivo cuidadoso e crítico, apresenta-se como caminho alternativo a esse estado de coisa. E como forma de resistir ao modelo educativo hegemônico que, ao simplesmente estender o tempo de permanência de todos na escola, perde de vista o que de fato significa educação integral.

\section{Referências}

AGUIAR, Wanda Maria Junqueira de; SOARES, Júlio Ribeiro; MACHADO Virgínia Campos. Núcleos de Significação: uma proposta histórico-dialética de apreensão das significações. Cadernos de Pesquisa, v.45 n.155 p.56-75 jan. /mar. 2015.

AGUIAR, Wanda Maria Junqueira de; OZELLA, Sergio. Apreensão dos sentidos: aprimorando a proposta dos núcleos de significação. Revista Brasileira de Estudos Pedagógicos, Brasília, v. 94, n. 236, p. 299-322, jan. /abr. 2013. Disponível em: http://www.scielo.br/pdf/rbeped/v94n236/15.pdf Acesso em: 22 ago. 2019.

AGUIAR, Wanda Maria Junqueira de. A pesquisa junto a professores: fundamentos teóricos e metodológicos”. In: AGUIAR, Wanda Maria Junqueira de (Org.) Sentidos e Significados do Professor na Perspectiva Sócio-Histórica: relatos de pesquisa. São Paulo: Casa do Psicólogo, 2006. 130p. 
ALMEIDA, Laurinda Ramalho de; PLACCO, Vera Maria Nigro de Souza. O Coordenador Pedagógico e questões de contemporaneidade.6 ed. São Paulo: Loyola, 2012. 144p.

ARENDT, Hannah. A Condição Humana. Trad. Roberto Raposo. 10. ed. Rio de Janeiro: Forense Universitária, 2008. 352p.

ARROYO, Miguel G. A humana docência. In: Ofício de Mestre: imagens e auto-imagens. $3^{\text {a }}$ ed. Petrópolis: Vozes, 2000. p. 50-67.

ARROYO, Miguel Gonzales. O direito ao tempo de escola. Cadernos de Pesquisa, s.l., n. 65, p. 3-10, 1988.

BALL, Stephen J. The Education Debate. The Policy Press. Bristol: University of Bristol, 2008.

BALL, Stephen J.; MAGUIRE, Meg; BRAUN, Annette. How schools do policy. Policy enactments in secondary schools. London, USA, Canada: Routledge, 2012.

BRASIL. Ministério da Educação. Parâmetros Curriculares Nacionais: terceiro e quarto ciclos: apresentação dos temas transversais/ Secretaria de Educação Fundamental. Brasília, DF: MEC/SEF, 1998. 436 p. http://portal.mec.gov.br/seb/arquivos/pdf/ttransversais.pdf. Acesso em: 11 abr. 2019.

BRASIL. Ministério da Educação. Educação integral: texto referência para o debate nacional. [Série Mais Educação]. Brasília, DF: MEC, SECAD, 2009. 52 p. Disponível em: http://educacaointegral.mec.gov.br/images/pdf/bibioteca/cadfinal_educ_integral.pdf. Acesso em: 11 abr. 2019.

BRASIL. Ministério da Educação. Caminhos para elaborar uma proposta de Educação Integral em Jornada Ampliada. Brasília: SEB/MEC, 2011. 64p. [Série Mais Educação]. Disponível http://educacaointegral.mec.gov.br/images/pdf/bibioteca/caminhos_elaborar_educ_integral_cecipe_seb.pdf. Acesso em: 11.abr.2019.

BRASIL. Ministério da Educação. Portaria MEC n. 1144 de 10 de outubro de 2016. Institui o Programa Novo Mais Educação que visa melhorar a aprendizagem em língua portuguesa e matemática no ensino fundamental. Brasília, DF: Diário Oficial da União, n. 196, 11 out. 2016, p.23.

BRASIL. Lei n.13.415. de 16 de fevereiro de 2017. Altera as Leis $\mathrm{n}{ }^{\circ} 9.394$, de 20 de dezembro de 1996 (...); e institui a Política de Fomento à Implementação de Escolas de Ensino Médio em Tempo Integral. Disponível em: http://www.planalto.gov.br/ccivil_03/_ato2015-2018/2017/lei/113415.htm. Acesso em: 31. ago. 2019.

CAVALIERE, Ana Maria. Anísio Teixeira e a Educação Integral. Paidéia, v.20, n.46, p.249-259, mai./ago. 2010. Disponível http://www.scielo.br/pdf/paideia/v20n46/11.pdf. Acesso em: 31 ago.2019.

CHIZZOTTI, Antônio; PONCE, Branca Jurema. O currículo e os sistemas de ensino no Brasil. Currículo Sem Fronteiras, v. 12, n. 3, p. 25-36, set./dez. 2012. Disponível em: http://www.curriculosemfronteiras.org/vol12iss3articles/chizzotti-ponce.pdf. Acesso em: 31 out. 2018.

COLL, César; POZO, Juan Ignácio; SARABIA, Barnabé; VALLS, Enric. Os conteúdos na reforma. Ensino e aprendizagem de conceitos, procedimentos e atitudes. Porto Alegre: Artes Médicas, 2000. 182p.

DELORS, Jacques. Educação: um tesouro a descobrir. 5. ed. São Paulo: Cortez/Brasília DF: MEC/UNESCO, 2001. 288p.

DOURADO, Luiz Fernandes; OLIVEIRA, João Ferreira de A qualidade da educação: perspectivas e desafios. Cadernos CEDES, v. 29, n. 78, p.201-215, mai./ago. 2009. Disponível em: http://www.scielo.br/pdf/ccedes/v29n78/v29n78a04.pdf Acesso em: 11 set. 2019. 
DUARTE, Newton. As pedagogias do "aprender a aprender" e algumas ilusões da assim chamada sociedade do conhecimento. Rev. Bras. Educ., Rio de Janeiro, n. 18, p. 35-40, dez. 2001. Disponível em:http://www.scielo.br/pdf/rbedu/n18/n18a04.pdf Acesso em: 11 set. 2019.

ESTEVES, José M. O Mal-Estar Docente: a sala de aula e a saúde dos professores. Bauru. EDUSC, 1999.

FREITAS, Luiz Carlos de. Os Reformadores Empresariais da Educação e a disputa pelo controle do processo pedagógico na Escola. Educação e Sociedade, Campinas, v. 35, n. 129, p. 1085-1114, 2014. Disponível em: http://www.scielo.br/pdf/es/v35n129/0101-7330es-35-129-01085.pdf Acesso em: 14 ago. 2019

FULLAN, Michael; HARGREAVES, Andy. A escola como como organização aprendente. Buscando uma educação de qualidade. $2^{\mathrm{a}}$. ed. Porto Alegre: Artmed, 2000

GARCIA, Paulo Sérgio; PREARO, Leandro (Orgs.). Avaliação da educação escolar no Grande ABC Paulista: primeiras aproximações. São Paulo: Plêiade, 2015. 181p.

HYPOLITO, Álvaro Moreira; VIEIRA, Jarbas dos S., LEITE, Maria Cecília L. Currículo, gestão e trabalho docente. Revista e-Curriculum, v.8, n. 2, p.1-16, ago. 2012. Disponível em: https://revistas.pucsp.br/curriculum/article/view/10989/8109 Acesso em: 11 set. 2019.

IBIAPINA, Ivana M. Lopes de Melo. Pesquisa Colaborativa. Investigação, formação e produção de conhecimentos. Brasília: Líber Livro Editora, 2008, 136p. (Série Pesquisa)

MOLL, Jaqueline (Org.). Caminhos da educação integral no Brasil: direitos a outros tempos e espaços educativos. Porto Alegre: Penso, 2012. 503p.

NAGLE, Jorge. Sociedade e Educação na Primeira República, 2ª . ed. Rio de Janeiro: DP\&A, 2001.

NÓVOA, Antônio. Profissão professor. 2a . ed. Porto: Porto Editora, 1999 (Coleção Ciências da Educação).

PÉREZ GÓMEZ, Angel Ignacio. A cultura escolar na sociedade neoliberal. Porto Alegre: ARTMED Editora, 2001.

PERRENOUD, Philippe. Dez novas competências para ensinar. Trad. Patrícia Chittoni Ramos, Porto Alegre: Artmed, 2000.

PONCE, Branca Jurema; ROSA, Sanny S. da. Políticas curriculares do estado brasileiro, trabalho docente e função dos professores como intelectuais. Revista Teias, v. 15, n. 39, p.43-58, 2014. Disponível em: https://www.epublicacoes.uerj.br/index.php/revistateias/article/view/24481. Acesso em: 19 set. 2019.

SÃO PAULO. Secretaria de Educação. Diretrizes do Programa Ensino Integral. Escola de Tempo Integral. São Paulo: s/d. Disponível em: http://www.educacao.sp.gov.br/a2sitebox/arquivos/documentos/342.pdf Acesso em: 14 set. 2019.

SACRISTÁN, Jose Gimeno. Consciência e ação sobre a prática como libertação profissional dos professores. In: NÓVOA, Antônio. Profissão Professor. Porto: Porto Editora, 1999.

YOUNG, Michael F. D.. Por que o conhecimento é importante para as escolas do século XXI?. Cad. Pesqui., São Paulo, v. 46, n. 159, p. 18-37, mar. 2016. Disponível em: https://doi.org/10.1590/198053143533. Acesso em: 01 jun. 2020. 